\title{
Public debt, discretionary policy, and inflation persistence *
}

\author{
Stefan NIEMANN ${ }^{\dagger} \quad$ Paul PICHLER ${ }^{\ddagger} \quad$ Gerhard SORGER ${ }^{\S}$
}

February 3, 2011

\begin{abstract}
We describe a simple mechanism that generates inflation persistence in a standard sticky-price model of optimal fiscal and monetary policy. Key to this mechanism is that policies are decided under discretion. The government's discretionary incentive to erode the real value of nominal public debt by means of surprise inflation renders inflation expectations and, in further consequence, equilibrium inflation rates highly correlated with the stock of public debt. Debt, in turn, is highly persistent to allow for tax-smoothing in the face of disturbances and, due to the aforementioned correlation, this persistence carries over to inflation. Our analysis shows a non-monotonic effect of nominal rigidities on inflation persistence and reveals further important differences between optimal policies under discretion versus commitment. Most notably, government debt under discretion does not display the near random walk property familiar from the Ramsey literature.
\end{abstract}

JEL classification: E31, E32, E61, E63

Keywords: Inflation dynamics; persistence; optimal fiscal and monetary policy; lack of commitment

\footnotetext{
* Previous versions of this paper have been circulated under the titles Optimal Fiscal and Monetary Policy Without Commitment and Inflation dynamics under optimal discretionary fiscal and monetary policies. We thank Sanjay Chugh, Wouter Den Haan, Christian Ghiglino, Ken Judd, Eric Leeper, Fernando Martin, Monika Merz, Salvador Ortigueira, Michael Reiter, Stefanie Schmitt-Grohé, Martin Uribe, and seminar and conference participants at the European Central Bank, the University of Osnabrück, the University of Basel, the Verein für Socialpolitik Annual Meeting (2008, Graz), the 5th European Workshop in Macroeconomics (2009, Mannheim) and the North American Summer Meeting of the Econometric Society (2009, Boston) for valuable comments and suggestions. The views expressed in this paper are solely the responsibility of the authors and should not be interpreted as reflecting the views of the Oesterreichische Nationalbank.

${ }^{\dagger}$ Corresponding author. Department of Economics, University of Essex, Wivenhoe Park, Colchester, Essex CO4 3SQ, United Kingdom. E-mail: sniem@essex.ac.uk

${ }^{\ddagger}$ Economic Studies Division, Oesterreichische Nationalbank, Vienna, Austria. E-mail: paul.pichler@oenb.at

${ }^{\S}$ Department of Economics, University of Vienna, Hohenstaufengasse 9, A-1010 Vienna, Austria. E-mail: gerhard.sorger@univie.ac.at
} 


\section{Introduction}

Ramsey models of fiscal and monetary policy typically predict inflation rates that are negative on average and display almost zero persistence (Chari, Christiano, and Kehoe, 1991; Khan, King, and Wolman, 2003; Schmitt-Grohe and Uribe, 2004; Siu, 2004). This empirically implausible prediction has recently been stressed by Chugh (2006), who shows that an otherwise standard Ramsey model augmented with habits-in-consumption preferences and physical capital accumulation features substantial inflation persistence. In his model, an increased preference or ability to smooth consumption over time leads to a highly persistent real interest rate; a persistent real interest rate, in turn, implies a persistent inflation rate by the Fisher relationship.

The present paper describes an alternative mechanism that generates optimal inflation persistence. We study a standard Ramsey-type sticky-price model and argue that, if policies are implemented under discretion rather than commitment, optimal inflation rates are highly persistent. Key to this result is the government's discretionary incentive to erode the real value of outstanding liabilities by means of surprise inflation. This incentive renders inflation expectations and, in further consequence, equilibrium inflation rates correlated with the level of outstanding debt. Public debt, in turn, is used under optimal policies as a means to smooth tax distortions over time and thus displays a high degree of persistence. Due to the aforementioned correlation, this persistence carries over to inflation.

Nominal rigidity affects inflation persistence in a non-monotonic way, as two opposing effects are at work. On the one hand, the correlation between debt and inflation becomes weaker as price variations become more costly. On the other hand, the persistence of debt under optimal policies increases in the presence of nominal rigidities; when price adjustments are costly the policy-maker refrains from using inflation as a shock absorber but uses persistent changes in debt to smooth the adverse effects of shocks over time. Whether an increase in price stickiness raises or lowers inflation persistence depends critically on which of the two effects is stronger. In a calibrated economy we show that at very low levels of price stickiness the reduced correlation effect dominates such that inflation persistence decreases in the amount of price stickiness. At larger levels of price stickiness, the debt persistence effect dominates and inflation persistence accordingly increases.

Our results show further important differences between optimal policies under commitment and discretion. Most notably, the dynamic properties of debt are qualitatively different between these two institutional environments. Under commitment, debt is used by the government to smooth the distortionary effects of shocks over time and displays a near random walk property, i.e., temporary innovations in the public budget are financed by permanent changes in taxes and debt (Schmitt-Grohe and Uribe, 2004). Under discretion, variations in the debt-stock in response to adverse shocks are costly, as they bring about increases in inflation expectations. These, in turn, lead to higher realized inflation rates in equilibrium and therefore higher price adjustment costs and higher nominal interest rate distortions. In light of these costs, the government feels compelled to keep debt in close vicinity of its steady state level. Importantly, this implies that unlike in the Ramsey framework temporary innovations in the public budget are not financed by permanent changes in taxes and debt, i.e., the random walk behavior of taxes and debt observed under commitment is overturned under discretion.

The remainder of the present paper is organized as follows. Section 2 lays out the model economy 
and characterizes the private-sector equilibrium for given policies. Section 3 presents the optimal policy problem. Section 4 discusses the calibration and numerical solution of the model. Section 5 presents our main findings. Section 6 discusses the related literature. Section 7 concludes.

\section{The model}

We consider an infinite-horizon production economy populated by a large number (a continuum of measure 1) of identical private agents and a government. The private agents act both as consumers and as producers; they operate under imperfect competition and set nominal prices subject to price adjustment costs. A demand for money arises due to its role in facilitating consumption transactions. Time evolves in discrete periods $t \in\{0,1,2, \ldots\}$.

\subsection{The private sector}

The preferences of the representative private agent are defined over sequences of consumption, $\left(c_{t}\right)_{t=0}^{\infty}$, and labor effort, $\left(h_{t}\right)_{t=0}^{\infty}$, and are given by

$$
E_{0} \sum_{t=0}^{\infty} \beta^{t}\left[u\left(c_{t}\right)-\alpha h_{t}\right],
$$

where $E_{0}$ denotes the mathematical expectation operator conditional on information available in period $0, \beta \in(0,1)$ is the time-preference factor, and $\alpha>0$ is the constant marginal utility of leisure. We assume that the function $u$ satisfies standard monotonicity, curvature, and smoothness properties.

The agent enters period $t$ holding $M_{t}$ units of money and $B_{t}$ units of one-period risk-free bonds issued by the government. Each of these bonds pays one unit of money when it matures at the end of period $t$. The agent has two sources of income in period $t$. First, it supplies $h_{t}$ units of labor to a perfectly competitive labor market earning the nominal after-tax wage income $\left(1-\tau_{t}\right) W_{t} h_{t}$, where $\tau_{t}$ and $W_{t}$ denote the tax rate and the nominal wage rate, respectively, in period $t$. Second, it earns profits from producing a differentiated intermediate good, which forms an input for the production of the final consumption good. Each agent has access to a linear production technology $\tilde{y}_{t}=a_{t} \tilde{h}_{t}$, which takes labor $\tilde{h}_{t}$ as the only input and is subject to a stochastic productivity $a_{t}$. Notice that, while $h_{t}$ is the agent's own labor supply, $\tilde{h}_{t}$ is the amount of labor it demands on the labor market to produce the intermediate good. Labor productivity $a_{t}$ is the same for all agents and evolves according to

$$
\log a_{t+1}=\rho_{a} \log a_{t}+\varepsilon_{t+1}^{a},
$$

where $\rho_{a}$ measures the autocorrelation of labor productivity and $\varepsilon_{t+1}^{a} \sim N\left(0, \sigma_{\varepsilon^{a}}^{2}\right)$ denotes the period$(t+1)$ innovation.

The final consumption good is a Dixit-Stiglitz aggregate of all intermediate goods. We denote by $\theta>1$ the constant elasticity of substitution between any two intermediate inputs. When $\theta \rightarrow \infty$, the economy approaches the limiting case of perfectly competitive product markets. Denoting by $\tilde{P}_{t}$ the price of an intermediate good charged by its monopolistic producer and by $P_{t}$ the aggregate price 
level, the demand for the intermediate good depends on aggregate output $y_{t}$ and the relative price $\tilde{P}_{t} / P_{t}$ according to

$$
d\left(\tilde{P}_{t}, P_{t}, y_{t}\right)=y_{t}\left(\tilde{P}_{t} / P_{t}\right)^{-\theta}
$$

When choosing its price $\tilde{P}_{t}$, the agent takes the demand function $d$ together with the aggregate variables $P_{t}$ and $y_{t}$ as given. Finally, we assume that there are quadratic costs to price adjustment as in Rotemberg (1982), which in real terms amount to

$$
\frac{\kappa}{2}\left(\tilde{P}_{t} / \tilde{P}_{t-1}-1\right)^{2}
$$

The parameter $\kappa$ in (2) measures the size of price adjustment costs. When $\kappa=0$ prices are flexible.

Finally, we follow Schmitt-Grohe and Uribe (2004) and postulate that each agent has to pay a proportional transaction cost $s\left(v_{t}\right)$ when purchasing $c_{t}$ units of the consumption good. Here, $v_{t}$ is the agent's consumption-based money velocity defined by

$$
v_{t}=P_{t} c_{t} / M_{t}
$$

Hence money is valued because it facilitates transactions. Notice that the timing assumption underlying the definition of velocity in (3) implies that the agents cannot reduce their transaction costs by rearranging their nominal asset portfolios at the start of a period, but that they are bound by their predetermined money holdings $M_{t}$. Thus, the velocity-based transaction cost $s\left(v_{t}\right)$ reflects a timing assumption corresponding to the cash-in-advance setting in Svensson (1985). As for the function $s$ itself we assume that (i) $s$ takes non-negative values and is twice continuously differentiable with first and second derivative $s_{v}$ and $s_{v v}$, (ii) there exists a satiation level $\underline{v}>0$ such that $s(\underline{v})=s_{v}(\underline{v})=0$, (iii) $(v-\underline{v}) s_{v}(v)>0$ for all $v \neq \underline{v}$, and (iv) $2 s_{v}(v)+v s_{v v}(v)>0$ for all $v \geq \underline{v}$. As discussed by Schmitt-Grohe and Uribe (2004) these assumptions guarantee that money demand is decreasing in the nominal interest rate and that the Friedman rule is not associated with an infinite money demand.

Finally, the agent's budget constraint in period $t$ is given by

$$
\begin{aligned}
M_{t}+ & B_{t}+\left(1-\tau_{t}\right) P_{t} w_{t} h_{t}+\tilde{P}_{t} y_{t}\left(\tilde{P}_{t} / P_{t}\right)^{-\theta}-P_{t} w_{t} \tilde{h}_{t}-(\kappa / 2)\left(\tilde{P}_{t} / \tilde{P}_{t-1}-1\right)^{2} P_{t} \\
& \geq P_{t} c_{t}\left[1+s\left(v_{t}\right)\right]+M_{t+1}+q_{t} B_{t+1},
\end{aligned}
$$

where $q_{t}$ denotes the price of bonds purchased in period $t$, i.e. $q_{t}$ is the inverse of the gross nominal interest rate on these bonds.

\subsection{The government}

The government is benevolent and decides over monetary and fiscal policy instruments. It faces a stream of exogenous, stochastic, and unproductive expenditures $\left(g_{t}\right)_{t=0}^{\infty}$, which evolves according to

$$
\log g_{t+1}=\left(1-\rho_{g}\right) \log \bar{g}+\rho_{g} \log g_{t}+\varepsilon_{t+1}^{g} .
$$


The parameter $\bar{g}$ denotes the steady state government expenditures, $\rho_{g}$ is the autocorrelation coefficient, and $\varepsilon_{t+1}^{g} \sim N\left(0, \sigma_{\varepsilon^{g}}^{2}\right)$. To finance its expenditures, the government imposes a proportional labor income tax at rate $\tau_{t}$, issues government bonds $\bar{B}_{t+1}$, and receives seignorage income $\bar{M}_{t+1}-\bar{M}_{t} \cdot{ }^{1}$ Monetary policy manages the supply of money $\bar{M}_{t+1}$ and sets the price of bonds $q_{t}$. The consolidated government budget constraint in nominal terms is thus given by

$$
\tau_{t} W_{t} h_{t}+\left(\bar{M}_{t+1}-\bar{M}_{t}\right)+q_{t} \bar{B}_{t+1} \geq P_{t} g_{t}+\bar{B}_{t}
$$

The policy instruments $\tau_{t}, \bar{B}_{t+1}, q_{t}$, and $\bar{M}_{t+1}$ must be chosen in such a way that (5) holds and that the markets for bonds and money clear.

\subsection{Private-sector equilibrium}

The individual household takes aggregate output, the wage rate, the price level, and the government's policies as given and maximizes lifetime utility subject to its budget constraint. The Lagrangian associated with this optimization problem reads

$$
\begin{aligned}
& \mathcal{L}^{H}=E_{0} \sum_{t=0}^{\infty} \beta^{t}\left\{u\left(\frac{v_{t} m_{t}}{1+\pi_{t}}\right)-\alpha h_{t}+\lambda_{t}\left[\frac{m_{t}+b_{t}}{1+\pi_{t}}+\left(1-\tau_{t}\right) w_{t} h_{t}+y_{t}\left(\tilde{p}_{t}\right)^{1-\theta}\right.\right. \\
& \left.\left.-\frac{w_{t}}{a_{t}} y_{t}\left(\tilde{p}_{t}\right)^{-\theta}-\frac{\kappa}{2}\left(\frac{\tilde{p}_{t}}{\tilde{p}_{t-1}}\left(1+\pi_{t}\right)-1\right)^{2}-\frac{v_{t} m_{t}}{1+\pi_{t}}\left[1+s\left(v_{t}\right)\right]-m_{t+1}-q_{t} b_{t+1}\right]+\nu_{t}\left[c_{t}-\frac{v_{t} m_{t}}{1+\pi_{t}}\right]\right\} .
\end{aligned}
$$

In the above representation we have eliminated the variable $\tilde{h}_{t}=y_{t}\left(\tilde{P}_{t} / P_{t}\right)^{-\theta} / a_{t}$ and we have introduced the real money holdings $m_{t+1}=M_{t+1} / P_{t}$, real bond holdings $b_{t+1}=B_{t+1} / P_{t}$, the relative price $\tilde{p}_{t}=\tilde{P}_{t} / P_{t}$, and the net inflation rate $\pi_{t}=P_{t} / P_{t-1}-1$. Finally, $\lambda_{t}$ and $\nu_{t}$ denote Lagrangian multipliers.

The solution to the household's optimization problem is characterized by a set of standard firstorder optimality conditions. Imposing on these conditions that all private agents are identical and that markets clear, i.e. $\bar{m}_{t}=m_{t}, \bar{b}_{t}=b_{t}, \tilde{p}_{t}=1$, and $y_{t}=a_{t} h_{t}$, we obtain the following set of conditions that characterize a symmetric private-sector equilibrium for given government policies:

$$
\begin{aligned}
& 0=c_{t}-\frac{v_{t} m_{t}}{1+\pi_{t}}, \\
& 0=u^{\prime}\left(c_{t}\right)-\lambda_{t}\left[1+s\left(v_{t}\right)+v_{t} s^{\prime}\left(v_{t}\right)\right], \\
& 0=-\alpha+\lambda_{t}\left(1-\tau_{t}\right) w_{t}, \\
& 0=w_{t}-\frac{\theta-1}{\theta} a_{t}-\frac{\kappa}{\theta h_{t}} \pi_{t}\left(1+\pi_{t}\right)+\beta \frac{\kappa}{\theta h_{t}} E_{t} \frac{\lambda_{t+1}}{\lambda_{t}} \pi_{t+1}\left(1+\pi_{t+1}\right), \\
& 0=-\lambda_{t}+\beta E_{t} \frac{\lambda_{t+1}}{1+\pi_{t+1}}\left[1+v_{t+1}^{2} s^{\prime}\left(v_{t+1}\right)\right], \\
& 0=-\lambda_{t} q_{t}+\beta E_{t} \frac{\lambda_{t+1}}{1+\pi_{t+1}} .
\end{aligned}
$$

\footnotetext{
${ }^{1}$ Where necessary, we use bars to distinguish aggregate variables from their individual counterparts.
} 
The first three equations characterize the household's optimal choice of consumption, the consumptionbased money velocity, and the labor supply. Equations (10)-(12) are, respectively, a purely forwardlooking New Keynesian Phillips curve and the household's Euler equations for money and bonds.

Finally, notice that equations (7)-(9) and the aggregate resource constraint allow us to express the private-sector equilibrium realizations of $c_{t}, \lambda_{t}, \tau_{t}$, and $h_{t}$ as functions of other decision variables. Specifically,

$$
\begin{aligned}
& c_{t}=\tilde{c}\left(v_{t}, \pi_{t}, m_{t}\right)=v_{t} m_{t} /\left(1+\pi_{t}\right), \\
& \lambda_{t}=\tilde{\lambda}\left(v_{t}, \pi_{t}, m_{t}\right)=u^{\prime}\left(\frac{v_{t} m_{t}}{1+\pi_{t}}\right)\left[1+s\left(v_{t}\right)+v_{t} s^{\prime}\left(v_{t}\right)\right]^{-1}, \\
& \tau_{t}=\tilde{\tau}\left(v_{t}, \pi_{t}, m_{t}, w_{t}\right)=1-\frac{\alpha}{w_{t}}\left[u^{\prime}\left(\frac{v_{t} m_{t}}{1+\pi_{t}}\right)\right]^{-1}\left[1+s\left(v_{t}\right)+v_{t} s^{\prime}\left(v_{t}\right)\right], \\
& h_{t}=\tilde{h}\left(v_{t}, \pi_{t}, m_{t} ; a_{t}, g_{t}\right)=\frac{1}{a_{t}}\left[\left(\frac{v_{t} m_{t}}{1+\pi_{t}}\right)\left[1+s\left(v_{t}\right)\right]+g_{t}+\frac{\kappa}{2} \pi_{t}^{2}\right] .
\end{aligned}
$$

These functions will be useful to ease notation in the following section, in which we present the government's optimal policy problem.

\section{The optimal policy problem}

The government's objective is to maximize the lifetime utility (1) of the representative household by decentralizing the desired allocation via the appropriate choice of its policy instruments $\tau_{t}, q_{t}, b_{t+1}$, and $m_{t+1} \cdot{ }^{2}$ The government is, however, subject to a well-known time-inconsistency problem: it would like to use surprise inflation as a means to erode the real value of its nominal debt burden, since this policy resembles a lump-sum tax on the private sector's financial wealth. The Ramsey literature addresses this problem by assuming that the government can nevertheless commit to implement its (time-inconsistent) policy plans. In the present paper we depart from this assumption and study optimal policies implemented by a purely discretionary government. ${ }^{3}$

A convenient way to characterize optimal discretionary policies is to assume that the government actually consists of an infinite sequence of separate policy makers, one for each period. The policy maker who is in charge in period $k$ will be referred to as the period- $k$ government. This government seeks to maximize social welfare from period $k$ onwards, whereby it takes the behavior both of its later incarnations and of the private sector as given. The optimal policy problem therefore resembles a dynamic game between the private sector and all period- $k$ governments, where $k$ ranges from 0 to $+\infty$. The private sector acts as a Stackelberg follower, whereas the governments play Nash among each other and act as Stackelberg leaders against the private sector. For simplicity, and following the dominant approach in the macroeconomic literature, we restrict attention to stationary Markov-perfect equilibria of this policy game.

\footnotetext{
${ }^{2}$ Notice that as a consequence of money and bond market clearing conditions, however, the policy maker has only two degrees of freedom when choosing these variables.

${ }^{3}$ Recent contributions along these lines include Diaz-Gimenez, Giovannetti, Marimon, and Teles (2008), Martin (2009), and Niemann (2009), among others.
} 
In a Markov-perfect equilibrium, strategies depend only on a minimal payoff-relevant state of the economy. For the present model with sticky-prices this state is comprised of the variables $b, m, a$ and $g$, respectively. ${ }^{4}$ The government today anticipates how future policies depend on current policy via the state of the economy. Specifically, it perceives that, from the next period onwards, choices for $v, \pi, w, q, m^{\prime}, b^{\prime}$ are governed by the rules $\mathcal{V}, \Pi, \mathcal{W}, \mathcal{Q}, \mathcal{M}$, and $\mathcal{B}$ as in $v^{\prime}=\mathcal{V}\left(b^{\prime}, m^{\prime}, a^{\prime}, g^{\prime}\right)$, $\pi^{\prime}=\Pi\left(b^{\prime}, m^{\prime}, a^{\prime}, g^{\prime}\right)$, etc.

The optimization problem of the discretionary government is therefore given by:

$$
\max _{v, \pi, w, q, m^{\prime}, b^{\prime}} u(\tilde{c}(\cdot))-\alpha \tilde{h}(\cdot)+\beta E \mathcal{U}\left(b^{\prime}, m^{\prime}, a^{\prime}, g^{\prime}\right)
$$

subject to the constraints

$$
\begin{aligned}
& 0=\tilde{\tau}(\cdot) w \tilde{h}(\cdot)+m^{\prime}+q b^{\prime}-g-\frac{m+b}{1+\pi}, \\
& 0=\left(w-\frac{\theta-1}{\theta} a\right) \tilde{h}(\cdot) \tilde{\lambda}(\cdot)-\frac{\kappa}{\theta} \tilde{\lambda}(\cdot) \pi(1+\pi)+\beta \frac{\kappa}{\theta} E\left\{\tilde{\lambda}^{\prime}(\cdot) \Pi(\cdot)(1+\Pi(\cdot))\right\}, \\
& 0=\tilde{\lambda}(\cdot)-\beta E\left\{\frac{\tilde{\lambda}^{\prime}(\cdot)\left[1+\mathcal{V}(\cdot)^{2} s^{\prime}(\mathcal{V}(\cdot))\right]}{(1+\Pi(\cdot))}\right\}, \\
& 0=\tilde{\lambda}(\cdot) q-\beta E\left\{\frac{\tilde{\lambda}^{\prime}(\cdot)}{1+\Pi(\cdot)}\right\} .
\end{aligned}
$$

For better readability we have omitted the arguments of the functions $\tilde{c}, \tilde{h}, \tilde{\tau}, \tilde{\lambda}, \mathcal{V}$, and $\Pi$. Notice further that, because all future governments are perceived to employ the policy rules $\mathcal{V}$, $\Pi$, etc., the continuation value function $\mathcal{U}\left(b^{\prime}, m^{\prime}, a^{\prime}, g^{\prime}\right)$ is implicitly defined by the recursion

$$
\mathcal{U}\left(b^{\prime}, m^{\prime}, a^{\prime}, g^{\prime}\right)=u\left(\tilde{c}\left(\mathcal{V}(\cdot), \Pi(\cdot), m^{\prime}\right)\right)-\alpha \tilde{h}\left(\mathcal{V}(\cdot), \Pi(\cdot), m^{\prime}\right)+\beta E \mathcal{U}\left(\mathcal{M}(\cdot), \mathcal{B}(\cdot), a^{\prime \prime}, g^{\prime \prime}\right)
$$

In a stationary Markov-perfect equilibrium all governments employ the same policy rules. These rules must thus satisfy the following property: if the current government perceives that all future governments employ the rules $\left\{\mathcal{V}^{*}, \Pi^{*}, \mathcal{W}^{*}, \mathcal{Q}^{*}, \mathcal{M}^{*}, \mathcal{B}^{*}\right\}$, the current government finds optimal to follow the very same policy rules $\left\{\mathcal{V}^{*}, \Pi^{*}, \mathcal{W}^{*}, \mathcal{Q}^{*}, \mathcal{M}^{*}, \mathcal{B}^{*}\right\}$. Therefore, no government will find it worthwhile to deviate and policies are time-consistent. Appendix A derives the first-order optimality conditions characterizing the stationary Markov-perfect equilibrium.

\section{Numerical Solution and Calibration}

For the model described in the previous section, the equilibrium policy functions cannot be computed in closed form. We thus resort to computational methods and derive numerical approximations to $\left\{\mathcal{V}^{*}, \Pi^{*}, \mathcal{W}^{*}, \mathcal{Q}^{*}, \mathcal{M}^{*}, \mathcal{B}^{*}\right\}$. Local approximation methods are not appropriate for this purpose because the model's steady-state around which local dynamics should be approximated is endogenously deter-

\footnotetext{
${ }^{4}$ Here and in what follows we use recursive notation, i.e. drop time indices and use primes to indicate next-period values.
} 
Table 1: Benchmark calibration: functional forms and parameter values

\begin{tabular}{ll} 
Description & Functional Form / Value \\
\hline Period utility function & $u(c)=\frac{c^{1-\sigma}-1}{1-\sigma}$ \\
Nominal rigidities (a la Rotemberg) & $\frac{\kappa}{2} \pi_{t}^{2}$ \\
Transaction cost function & $s(v)=A_{1} v+A_{2} / v-2 \sqrt{A_{1} A_{2}}$ \\
Discount factor & $\beta=1 / 1.04$ \\
Inverse of intertemporal elasticity of substitution & $\sigma=2$ \\
Marginal utility of leisure & $\alpha=10.4$ \\
Price elasticity of demand & $\theta=20$ \\
Size of price adjustment costs & $\kappa=0$ \\
Transaction costs & $A_{1}=0.137$ \\
Transaction costs & $A_{2}=2.3$ \\
Steady-state government expenditures & $\bar{g}=0.06$ \\
Persistence of government expenditures & $\rho_{g}=0.8$ \\
Expenditure innovation volatility & $\sigma_{g}=0.04$ \\
Persistence of technology process & $\rho_{a}=0.82$ \\
Technology innovation volatility & $\sigma_{a}=0.023$ \\
\hline
\end{tabular}

mined as part of the model solution and thus a priori unknown. In light of this difficulty, we resort to a global solution method. Specifically, we employ the Galerkin projection method described in Judd (1992) and compute fourth-order accurate polynomial approximations to the equilibrium policy functions. ${ }^{5}$

Before solving the model numerically, functional forms must be specified and values must be assigned to structural parameters. Table 1 summarizes our choices. We set $\beta=1 / 1.04$, which is a standard value for models with annual data. The utility function $u$ is assumed to be of the CES type, with the inverse of the intertemporal elasticity of substitution being equal to $\sigma=2$. This value is in the middle of the parameter range typically considered in the literature. The elasticity of substitution between intermediate goods is chosen as $\theta=20$, which implies a monopolistic mark-up of approximately $5 \%$ similar to Siu (2004). As for the price adjustment cost parameter $\kappa$ we will postulate different numerical values. In our benchmark calibration prices are flexible $(\kappa=0)$, but later on we consider values up to $\kappa=2$ (which is equivalent to a Calvo parameter implying that firms re-optimize prices every 6-7 months; see Keen and Wang, 2007). The technology parameters are set to $\rho_{a}=0.82$ and $\sigma_{a}=0.023$ as in Schmitt-Grohe and Uribe (2004). The preference parameter $\alpha$ is selected such that labor supply in steady state is roughly equal to one third of the time endowment; this yields $\alpha=10.4$. The remaining parameters are chosen in line with U.S. data for 1960-2006 available from Martin (2009). Government expenditure in steady state is set to $\bar{g}=0.06$ corresponding to roughly $18 \%$ of output, $\rho_{g}=0.8$ matching the autocorrelation coefficient of government expenditures in the data, and $\sigma_{g}=0.04$ such that government spending differs by roughly four percentage points from

\footnotetext{
${ }^{5}$ Given that our model has four state variables, higher-order approximations are computationally infeasible. Numerical accuracy checks show, however, that the fourth-order approximation is sufficiently accurate for our purposes. Normalized errors in the model's Euler equations are well below $0.01 \%$ of consumption, such that the key simulation results can be considered immune to approximation error.
} 
its average. Finally, the transaction cost function is parameterized as $s(v)=A_{1} v+A_{2} / v-2 \sqrt{A_{1} A_{2}}$, where $A_{1}=0.137$ and $A_{2}=2.3$. The calibration of $A_{1}$ and $A_{2}$ ensures that the model generates the steady state velocity $v^{*}=4.3$, which is in line with the average velocity in the U.S. data for $M 1$, and the government debt-to-GDP ratio approximately equal to $30 \%{ }^{6}$

\section{Results}

This section contains the main results of our analysis. We first show that, irrespective of the degree of nominal rigidities, inflation rates under discretionary policies are positive on average and persistent. In particular, we provide a detailed analysis of the mechanism generating these dynamic properties. We then turn to the dynamics of public debt under sticky prices and show that, unlike in the Ramsey framework, debt does not display a near random walk behavior.

\subsection{Optimal policy dynamics and inflation persistence}

Table 2 presents several simulation-based moments for the key variables in our model: inflation, the net nominal interest rate, labor taxes, output, consumption, and real debt. The values reported are computed as averages over 500 simulations, with each simulation including 1.000 time periods.

Our central observation from Table 2 is that inflation rates are positive on average and persistent, and that these (qualitative) properties obtain independent of whether prices are flexible or sticky. ${ }^{7}$ This contrasts sharply with findings in the Ramsey literature (Schmitt-Grohe and Uribe, 2004; Khan, King, and Wolman, 2003) according to which optimal inflation typically ranges between zero and the (negative) value called for by the Friedman rule, and displays almost zero persistence. The intuition behind this striking difference in optimal policy prescriptions is best understood as follows. First, to see why inflation rates are positive, note that in our environment $\sigma>1$ and therefore future consumption is inelastic relative to current consumption. This gives the government a discretionary incentive to trade current distortions for future distortions, i.e., to increase current consumption at the expense of higher future indebtedness. ${ }^{8}$ In equilibrium, this intertemporal elasticity effect must be balanced by economic costs associated with increasing current consumption. As is evident from equation (3), an increase in consumption can either be accommodated via a decrease in the price level or an increase in velocity. Hence, costs from a discretionary increase in consumption arise if and only if both these channels are costly to exercise. For deflation to be costly the amount of outstanding nominal debt must be positive such that the price effect raises the real value of the government's liabilities (Martin, 2009). For increases in velocity to be costly, $v$ must be above the satiation level $\underline{v}$. This effect drives monetary policy away from the Friedman rule, and we observe positive nominal

\footnotetext{
${ }^{6}$ Government debt in our model relates to the net asset position between the private and the public sector, and its empirical counterpart, therefore, is not gross federal debt but government debt held by the public net of holdings by Federal Reserve Banks. This debt aggregate was on average roughly 30\% of GDP over 1960-2006, and has recently peaked at 47\% of GDP in December 2009 (Council of Economic Advisers, 2010, p. 426).

${ }^{7}$ The quantitative effects of price stickiness on inflation dynamics are of course not negligible. In particular, a modest degree of rigidity has substantial effects on the inflation dynamics; with $\kappa=0.5$ average annual inflation is down to below $3 \%$ compared to approximately $26 \%$ under flexible prices.

${ }^{8}$ The argument is familiar from the cash-in-advance economies studied by Diaz-Gimenez, Giovannetti, Marimon, and Teles (2008) and Martin (2009).
} 
Table 2: Dynamics

\begin{tabular}{|c|c|c|c|c|c|c|}
\hline$x$ & $\operatorname{mean}(x)$ & $\operatorname{std}(x)$ & ( $\operatorname{corr}\left(x^{\prime}, x\right)$ & $\operatorname{corr}(x, y)$ & $\operatorname{corr}(x, a)$ & $\operatorname{corr}(x, g)$ \\
\hline \multicolumn{7}{|c|}{$\kappa=0$} \\
\hline$\pi$ & 26.8860 & 4.1799 & 0.7822 & 0.0087 & -0.3204 & 0.7577 \\
\hline$R$ & 31.9527 & 4.3741 & 0.9218 & 0.0425 & -0.3395 & 0.8737 \\
\hline$\tau$ & 15.2300 & 0.8307 & 0.7241 & 0.0712 & -0.3526 & 0.9177 \\
\hline$y$ & 0.3293 & 0.0068 & 0.8109 & 1.0000 & 0.9071 & 0.4195 \\
\hline$c$ & 0.2684 & 0.0066 & 0.8284 & 0.7100 & 0.9374 & -0.3371 \\
\hline$b$ & 0.1016 & 0.0025 & 0.7266 & 0.7090 & 0.7602 & 0.1194 \\
\hline \multicolumn{7}{|c|}{$\kappa=0.25$} \\
\hline$\pi$ & 4.055 & 1.2699 & 0.6398 & -0.2115 & -0.5551 & 0.6595 \\
\hline$R$ & 8.6677 & 1.7586 & 0.8575 & -0.4512 & -0.7326 & 0.6213 \\
\hline$\tau$ & 19.5394 & 1.2618 & 0.7922 & 0.1216 & -0.3297 & 0.9338 \\
\hline$y$ & 0.3289 & 0.0067 & 0.8412 & 1.0000 & 0.8913 & 0.4372 \\
\hline$c$ & 0.2684 & 0.0064 & 0.8662 & 0.6925 & 0.9324 & -0.3363 \\
\hline$b$ & 0.0980 & 0.0028 & 0.9068 & 0.0190 & 0.1030 & 0.4401 \\
\hline \multicolumn{7}{|c|}{$\kappa=0.5$} \\
\hline$\pi$ & 2.5744 & 0.9648 & 0.7129 & -0.1997 & -0.5443 & 0.6171 \\
\hline$R$ & 6.6534 & 1.5874 & 0.8354 & -0.4312 & -0.7766 & 0.5456 \\
\hline$\tau$ & 19.8609 & 1.2751 & 0.7851 & 0.1316 & -0.3396 & 0.9247 \\
\hline$y$ & 0.3289 & 0.0066 & 0.8447 & 1.0000 & 0.8822 & 0.4525 \\
\hline$c$ & 0.2685 & 0.0063 & 0.8768 & 0.6900 & 0.9323 & -0.3253 \\
\hline$b$ & 0.0919 & 0.0048 & 0.9691 & -0.0280 & -0.1167 & 0.4484 \\
\hline \multicolumn{7}{|c|}{$\kappa=1$} \\
\hline$\pi$ & 1.1429 & 0.6677 & 0.7879 & -0.1845 & -0.4758 & 0.5243 \\
\hline$R$ & 5.1588 & 1.3653 & 0.7990 & -0.5025 & -0.8152 & 0.4578 \\
\hline$\tau$ & 19.9525 & 1.2531 & 0.7782 & 0.1488 & -0.3310 & 0.9181 \\
\hline$y$ & 0.3291 & 0.0066 & 0.8461 & 1.0000 & 0.8674 & 0.4735 \\
\hline$c$ & 0.2688 & 0.0061 & 0.8848 & 0.6878 & 0.9331 & -0.3090 \\
\hline$b$ & 0.0762 & 0.0089 & 0.9889 & -0.0578 & -0.1670 & 0.3774 \\
\hline \multicolumn{7}{|c|}{$\kappa=2$} \\
\hline$\pi$ & 0.4544 & 0.3878 & 0.8000 & -0.1571 & -0.4050 & 0.4757 \\
\hline$R$ & 4.0825 & 1.5796 & 0.7856 & -0.4477 & -0.7545 & 0.4840 \\
\hline$\tau$ & 19.7160 & 1.3372 & 0.7816 & 0.1412 & -0.3237 & 0.9109 \\
\hline$y$ & 0.3296 & 0.0066 & 0.8469 & 1.0000 & 0.8661 & 0.4682 \\
\hline$c$ & 0.2694 & 0.0061 & 0.8889 & 0.6876 & 0.9274 & -0.3149 \\
\hline$b$ & 0.0504 & 0.0104 & 0.9932 & -0.0628 & -0.1311 & 0.3268 \\
\hline
\end{tabular}

Note: The numbers reported are computed as averages over $N=500$ simula tions, each simulation of length $T=1.000$. To make the comparison between the different panels of Table 2 meaningful, the same realizations of the model's two exogenous shocks are used for each panel.

interest rates in equilibrium. By the Fisher relationship, these translate into positive inflation rates. A similar argument explains why optimal inflation rates under discretion are persistent. Recall that, in an equilibrium with $\sigma>1$, it is not sufficient that increases in velocity are costly, but decreases in the price level must be costly, too. Such costs arise because government debt trades in nominal terms, implying that the deflation needed to increase current consumption hurts the government because it increases the real value of its liabilities. Put differently, the government generally has an incentive to create inflation in order to monetize nominal debt, the size of which depends strongly on the level of debt. In further consequence, the realized inflation rates are increasing in the level of debt.

This property is illustrated in Figure 1, which plots the equilibrium inflation policy as a function of 
Figure 1: Inflation policy under flexible and sticky prices

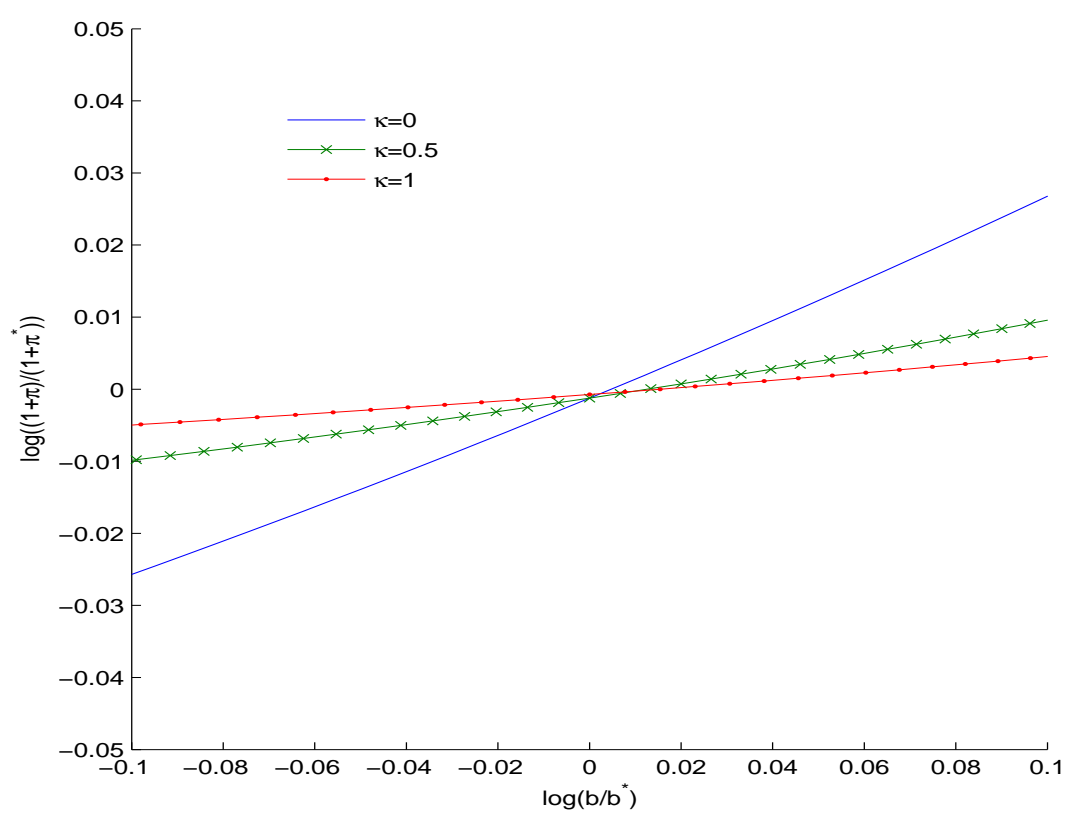

Note: On the horizontal axis we plot the percentage deviation of the debt-tomoney ratio from its steady state level, and on the vertical axis the percentage deviation of inflation from its steady state level. The technology and government expenditure levels are fixed at the steady state levels $a=1$ and $g=\bar{g}$, respectively.

the endogenous state variable $b$. On the other hand, the desire to smooth consumption in the face of stochastic shocks makes the government implement a relatively smooth path for debt, and the variable $b$ is, therefore, highly persistent. Debt persistence carries over to inflation due to the aforementioned correlation between the two variables.

Comparing the different panels of Table 2 we observe that the level of inflation decreases sharply in the price stickiness parameter $\kappa$. This reduction can be decomposed into two effects. The first and obvious effect is that, at all levels of government debt, the government chooses a lower inflation tax when accounting for resource losses due to price adjustment costs. The second effect is via the reduced (average) level of debt, which again reduces the incentive to monetize nominal liabilities and therefore inflation. To understand why the level of debt decreases due to price adjustment costs, recall that when prices are flexible, the discretionary government uses inflation as one of its main shock absorbers. The larger is the stock of debt, the better inflation can perform this role. Hence, besides its obvious negative effects on the government's budget constraint, a larger stock of debt can be helpful under flexible prices to stabilize the economy in response to shocks. Under sticky prices inflation is no longer used as a shock absorber and this positive effect of the debt-stock disappears. The policymaker thus has an incentive to further reduce the stock of debt. Finally, notice that while the level of inflation is clearly decreasing in $\kappa$, the effect of $\kappa$ on inflation persistence is non-monotonic. This latter property is emphasized in Figure 2 which plots the degree of inflation persistence (measured 
Figure 2: Inflation persistence and price stickiness

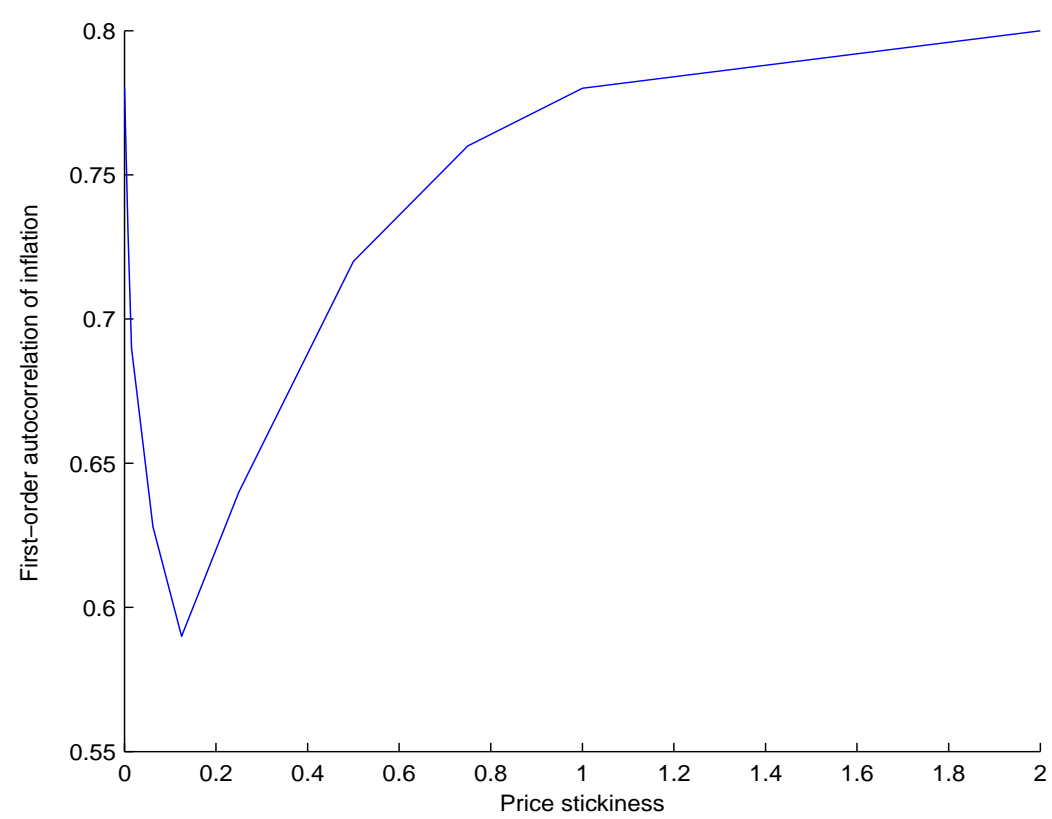

by the average first-order autocorrelation of the simulated inflation series) as function of the price stickiness parameter $(\kappa)$. At the flexible price benchmark inflation persistence sharply decreases in $\kappa$, but already at very low levels of $\kappa$ it starts to increase. The intuition behind this property is best understood as follows. Recall that, in the model under consideration, the level of government debt is the principal determinant of inflation. Specifically, the government's inflation incentives and, thus, equilibrium inflation are increasing in debt. Under sticky prices, the convexity of the price adjustment costs implies that the reduction of the government's inflation incentive is stronger at high levels of debt (or inflation). This property reduces the correlation between inflation and the level of debt, as confirmed by the policy functions depicted in Figure 1. Consequently, for a given degree of persistence in debt this effect leads to a lower degree of inflation persistence. On the other hand, introducing sticky prices increases the persistence of debt since it limits the shock-absorbing role of inflation (SchmittGrohe and Uribe, 2004; Siu, 2004). This latter effect leads to a higher degree of inflation persistence. Whether inflation persistence increases or decreases due to price stickiness depends therefore on which of the two effects dominates.

\subsection{Mean-reverting debt dynamics}

In the previous section we have argued that the persistence of debt increases considerably with the degree of price stickiness $\kappa$ and that the underlying mechanism is familiar from the Ramsey literature. This raises the question of whether debt under discretionary policies also displays the near random walk property familiar from this literature. In the following, we show that this is not the case.

To this end we examine whether a temporary innovation to the public budget is financed by a permanent increase in (taxes and) debt. Figure 3 displays the impulse response to an uncorrelated 
Figure 3: Impulse responses to an i.i.d. government purchases shock
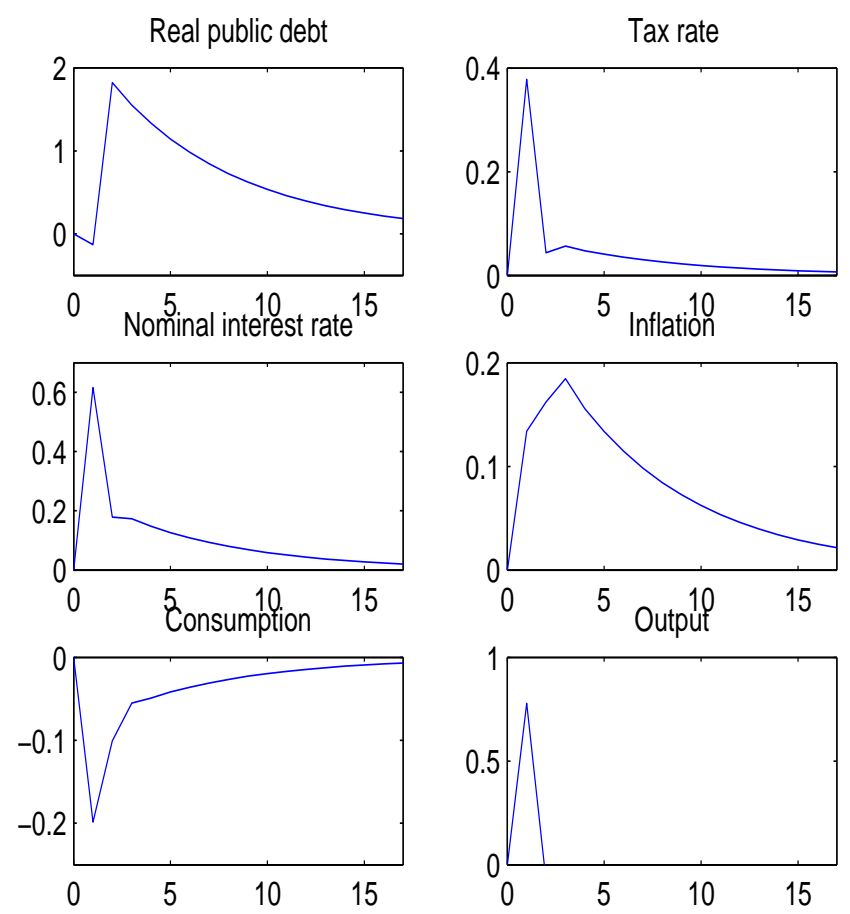

Note: The size of innovation in government purchases is one standard deviation. The shock takes place in period one. Public debt, consumption, and output are measured in percent deviations from their pre-shock values. The labor income tax rate, the nominal interest rate, and the inflation rate are measured in percentage points. Prices are sticky $(\kappa=1)$.

government purchases shock for a sticky price model with adjustment cost parameter $\kappa=1$. Notice that the pattern of adjustment shows that both taxes and debt return to their pre-shock values, unlike in the Ramsey framework (Schmitt-Grohe and Uribe, 2004). The government responds to an expenditure shock in period one by simultaneously issuing public debt, raising the tax rate, and printing money. ${ }^{9}$ This policy reduces private consumption and stimulates economic activity, such that the aggregate resource constraint holds at the higher level of public expenditure. In period two, government expenditure returns to its pre-shock level but the government has a higher amount of debt outstanding, which must be serviced in the following periods. As revealed by the impulse responses shown in Figure 3, the government essentially achieves this by means of higher taxes and a steady monetary expansion. The inflation rate reaches a maximum two years after the shock and then only gradually returns to its steady state level; several years after the shock has occurred inflation is still noticeably above its pre-shock level. On the other hand, the government in period two reduces the labor tax almost to the pre-shock level. This stimulates labor effort and helps to maintain a smooth consumption path, a feature of optimal policy that is again familiar from the Ramsey literature.

\footnotetext{
${ }^{9}$ Notice that nominal debt is initially inelastic, such that the instantaneous rise in the price level suppresses the real value of debt in period one.
} 


\section{Related Literature}

In terms of its central research question, the present paper contributes to a large literature concerned with inflation persistence. Fuhrer and Moore (1995) show that in the New Keynesian model nominal rigidities in the wage or price setting mechanism generate persistence in the price level but fail to produce persistence in inflation, and they suggest backward-looking wage contracting as a remedy for this implausible prediction. Gali and Gertler (1999) and Steinsson (2003) postulate that a fraction of producers set their prices according to a rule of thumb, whereas Christiano, Eichenbaum, and Evans (2005) propose partial indexation to past inflation. Recent papers have identified persistent changes in monetary policy as driving forces behind persistent inflation rates. Cogley and Sbordone (2008) and Ireland (2007) consider shifts in the central bank's inflation target that translate into drifts in trend inflation and, thus, induce inflation persistence. Similarly, Erceg and Levin (2003) propose a model of incomplete information where inflation persistence is generated via the private sector's signal extraction problem in the face of uncertainty about the monetary policy rule. Common to these contributions is their emphasis on exogenous changes in the monetary policy regime. Our paper complements this recent literature by presenting a model in which optimal macroeconomic policies are determined endogenously.

In terms of methodology, our paper contributes to a growing literature on time-consistent optimal policy. This literature formulates the policy problem as a game between successive governments, one for each time period, and analyzes Markov-perfect equilibria of this game. Ortigueira (2006) uses this approach to study optimal taxation under lack of commitment, focussing on the implications of different degrees of the government's within-period commitment. Klein, Krusell, and Rios-Rull (2008) study optimal government expenditures. Adam and Billi (2008) and Niemann (2009) study strategic monetary-fiscal interactions from an optimal taxation perspective. Diaz-Gimenez, Giovannetti, Marimon, and Teles (2008) examine the implications of indexed versus nominal debt on optimal policies; they show that nominal government debt can be a burden on monetary policy because it accentuates the monetary authority's time-inconsistency problem. Martin (2009) provides a positive theory of public debt; considering a cash-credit economy, he argues that the costs and benefits of surprise inflation pin down the equilibrium level of public debt.

\section{Conclusion}

This paper has examined the dynamic properties of inflation in a model of optimal fiscal and monetary policy under discretion. In this model, there is a single benevolent government which can only use distortionary tax instruments, but can issue nominal state-noncontingent debt to shift distortions over time. Under lack of commitment and with nominal public debt, the government's problem is to optimally trade off the benefits and costs of inflation. On the one hand, unanticipated inflation in our model is attractive since it reduces the real value of outstanding liabilities. On the other hand, inflation is costly because it reduces current consumption possibilities by increasing transaction costs. This critical trade-off generates a rationale for fiscal and monetary policies which lead to positive and persistent inflation rates in equilibrium. The key mechanism behind this finding is 
that the government's desire to smooth consumption implies that public debt is used as a shock absorber. Optimal discretionary policies generate persistent debt; and this persistence carries over to inflation. Our analysis furthermore shows a non-monotonic effect of nominal rigidities on inflation persistence and reveals further important differences between optimal policies under discretion versus commitment. Most notably, government debt under discretion does not display the near random walk property familiar from the Ramsey literature.

\section{References}

AdAm, K., AND R. M. Billi (2008): "Monetary conservatism and fiscal policy," Journal of Monetary Economics, 55(8), 1376-1388.

Christiano, L., M. Eichenbaum, and C. Evans (2005): "Nominal Rigidities and the Dynamic Effects of a Shock to Monetary Policy," Journal of Political Economy, 113(1), 1-45.

Cogley, T., and A. M. Sbordone (2008): "Trend Inflation, Indexation, and Inflation Persistence in the New Keynesian Phillips Curve," American Economic Review, 98(5), 2101-26.

Council of Economic Advisers (2010): Economic Report of the President. U.S. Government Printing Office.

Diaz-Gimenez, J., G. Giovannetti, R. Marimon, and P. Teles (2008): "Nominal Debt as a Burden on Monetary Policy," Review of Economic Dynamics, 11(3), 493-514.

Erceg, C. J., And A. T. Levin (2003): "Imperfect credibility and inflation persistence," Journal of Monetary Economics, 50(4), 915-944.

Fuhrer, J., And G. Moore (1995): "Inflation Persistence," The Quarterly Journal of Economics, 110(1), 127-59.

Gali, J., And M. Gertler (1999): "Inflation dynamics: A structural econometric analysis," Journal of Monetary Economics, 44(2), 195-222.

Ireland, P. N. (2007): "Changes in the Federal Reserve's Inflation Target: Causes and Consequences," Journal of Money, Credit and Banking, 39(8), 1851-1882.

JuDD, K. L. (1992): "Projection methods for solving aggregate growth models," Journal of Economic Theory, 58(2), 410-452.

Keen, B., And Y. WANG (2007): "What is a realistic value for price adjustment costs in New Keynesian models?," Applied Economics Letters, 14(11), 789-793.

Khan, A., R. G. King, and A. L. Wolman (2003): "Optimal Monetary Policy," Review of Economic Studies, 70(4), 825-860.

Klein, P., P. Krusell, and J.-V. Rios-Rull (2008): “Time-Consistent Public Policy," Review of Economic Studies, 75(3), 789-808. 
Martin, F. (2009): "A Positive Theory of Government Debt," Review of Economic Dynamics, 12(4), 608-631.

Niemann, S. (2009): "Dynamic Monetary-Fiscal Interactions and the Role of Monetary Conservatism," Economics Discussion Papers 667, University of Essex, Department of Economics.

Ortigueira, S. (2006): "Markov-Perfect Optimal Taxation," Review of Economic Dynamics, 9(1), $153-178$.

Schmitt-Grohe, S., And M. Uribe (2004): "Optimal fiscal and monetary policy under sticky prices," Journal of Economic Theory, 114(2), 198-230.

SiU, H. E. (2004): "Optimal fiscal and monetary policy with sticky prices," Journal of Monetary Economics, 51(3), 575-607.

Steinsson, J. (2003): "Optimal monetary policy in an economy with inflation persistence," Journal of Monetary Economics, 50(7), 1425-1456.

Svensson, L. E. O. (1985): "Money and Asset Prices in a Cash-in-Advance Economy," Journal of Political Economy, 93(5), 919-44. 


\section{Appendix A}

This Appendix details the government's optimality conditions that must be satisfied in a Markovperfect equilibrium. The optimal policy problem under discretion reads

$$
\max _{v, \pi, w, q, m^{\prime}, b^{\prime}}\left\{\frac{\tilde{c}(v, \pi, m)^{1-\sigma}-1}{1-\sigma}-\alpha \tilde{h}(v, \pi, m, a, g)+\beta E \mathcal{U}\left(m^{\prime}, b^{\prime}, a^{\prime}, g^{\prime}\right)\right\}
$$

subject to the implementability conditions

$$
\begin{aligned}
0 & =\tilde{\tau}(v, \pi, m, w) w \tilde{h}(v, \pi, m, a, g)+m^{\prime}+q b^{\prime}-g-\frac{m+b}{1+\pi} \\
0 & =\left(w-\frac{\theta-1}{\theta} a\right) \tilde{h}(v, \pi, m, a, g) \tilde{\lambda}(v, \pi, m)-\frac{\kappa}{\theta} \tilde{\lambda}(v, \pi, m) \pi(1+\pi) \\
& +\beta \frac{\kappa}{\theta} E\left\{\tilde{\lambda}\left(\mathcal{V}(\cdot), \Pi(\cdot), m^{\prime}\right) \Pi(\cdot)(1+\Pi(\cdot))\right\}, \\
0 & =\tilde{\lambda}(v, \pi, m)-\beta E\left\{\tilde{\lambda}\left(\mathcal{V}(\cdot), \Pi(\cdot), m^{\prime}\right) \frac{1+\mathcal{V}(\cdot)^{2} s^{\prime}(\mathcal{V}(\cdot))}{1+\Pi(\cdot)}\right\}, \\
0 & =\tilde{\lambda}(v, \pi, m) q-\beta E\left\{\tilde{\lambda}\left(\mathcal{V}(\cdot), \Pi(\cdot), m^{\prime}\right) \frac{1}{1+\Pi(\cdot)}\right\} .
\end{aligned}
$$

Given $\mathcal{V}$ and $\Pi$, and accounting for the arguments in the functions $\tilde{\tau}, \tilde{h}$, and $\tilde{\lambda}$ in the implementability constraints, we can write them as

$$
\begin{aligned}
& 0=\Sigma\left(m, b, a, g, v, \pi, w, q, m^{\prime}, b^{\prime}\right), \\
& 0=\Omega\left(m, a, g, v, \pi, w, m^{\prime}, b^{\prime}\right), \\
& 0=\Psi\left(m, a, g, v, \pi, m^{\prime}, b^{\prime}\right), \\
& 0=\Phi\left(m, a, g, v, \pi, q, m^{\prime}, b^{\prime}\right) .
\end{aligned}
$$

Let us denote by $\eta^{1}, \eta^{2}, \eta^{3}$ and $\eta^{4}$ the multipliers on these constraints. The first-order conditions for the government's problem under discretion then read:

$$
\begin{aligned}
0 & =\tilde{c}^{-\sigma} \tilde{c}_{v}-\alpha \tilde{h}_{v}+\eta^{1} \Sigma_{v}+\eta^{2} \Omega_{v}+\eta^{3} \Psi_{v}+\eta^{4} \Phi_{v}, \\
0 & =\tilde{c}^{-\sigma} \tilde{c}_{\pi}-\alpha \tilde{h}_{\pi}+\eta^{1} \Sigma_{\pi}+\eta^{2} \Omega_{\pi}+\eta^{3} \Psi_{\pi}+\eta^{4} \Phi_{\pi}, \\
0 & =\eta^{1} \Sigma_{w}+\eta^{2} \Omega_{w}, \\
0 & =\eta^{1} \Sigma_{q}+\eta^{4} \Phi_{q}, \\
0 & =\beta E\left\{\left(\tilde{c}^{\prime}\right)^{-\sigma} \tilde{c}_{m^{\prime}}^{\prime}-\alpha \tilde{h}_{m^{\prime}}^{\prime}+\eta^{1^{\prime}}\left(\Sigma_{m}\right)^{\prime}+\eta^{2^{\prime}}\left(\Omega_{m}\right)^{\prime}+\eta^{3^{\prime}}\left(\Psi_{m}\right)^{\prime}+\eta^{4^{\prime}}\left(\Phi_{m}\right)^{\prime}\right\} \\
& +\eta^{1} \Sigma_{m^{\prime}}+\eta^{2} \Omega_{m^{\prime}}+\eta^{3} \Psi_{m^{\prime}}+\eta^{4} \Phi_{m^{\prime}}, \\
0 & =\beta E\left\{\eta^{1^{\prime}}\left(\Sigma_{b}\right)^{\prime}\right\}+\eta^{1} \Sigma_{b^{\prime}}+\eta^{2} \Omega_{b^{\prime}}+\eta^{3} \Psi_{b^{\prime}}+\eta^{4} \Phi_{b^{\prime}} .
\end{aligned}
$$

The computation of the derivatives contained in the FOCs is tedious but straightforward. 